\title{
Market Orientation Determinants: Reflections from Academics in Universities of Technology in South
} Africa

\author{
B A Mokoena, M Dhurup \\ Vaal University of Technology, South Africa \\ aubrey@vut.ac.za
}

\begin{abstract}
Internationally, universities have come under increased pressure to respond to the changing market environment. A new axis for higher education institutions (HEIs) is a key to successful marketing, which lies in identifying the core business of institutions. Market orientation more closely reflects a philosophy that will not only serve to bring unity of purposes in HEIs, but serves as an indispensable tool that can assist HEIs to deliver their core business. The dynamics in the HE environment, the growth potential and the regulatory challenges make universities of technology (UoTs) ideal institutions for a study on the implementation of market orientation. It is against this backdrop that this paper considers the factors contributing to market orientation through the lenses of South African UoT academics through a quantitative study; 507 (n=507) academics participated in the study. Data are analysed through exploratory (to determine the factor structure) and confirmatory factor analysis (to confirm factor structure), descriptive and correlation analysis (to analyse the composition of the sample and to establish validity). Through the factor analysis procedure, seven factors were established, namely intelligence generation, inter-functional coordination, student-orientation, market intelligence dissemination, intelligence response design, intelligence response implementation and interdepartmental dynamics as a basis for operationalising the marketing orientation concept among UoTs. Through confirmatory factor analysis, the identified components seem to encapsulate the determinants of UoTs appropriately. From a practical standpoint, top management of universities could use these core market orientation factors to guide their strategic marketing plans and their strategic imperatives with the universities vision and mission in order to remain relevant and competitive. Future studies could expand these factors to provide a better understanding within HEIs in relation to their various stakeholders.
\end{abstract}

Keywords: Higher education institutions, universities of technology, market orientation, factor analysis and academics

\section{Introduction}

Competition, economic turbulence, government subsidy and reporting frameworks are underpinning elements, amongst others, of what public higher education institutions (HEIs) are contending with at present in South Africa as they can no longer rely on 'business as usual' (Altbach, 2010). This is hardly surprising. Giroux (2003) explains that universities are perceived as corporations influenced by business models of governance and reporting where accountability becomes the primary focus, as with corporations. In South Africa, higher education governance seems to be underpinned by the spirit of democracy, globalisation through internationalisation and a general shift towards market-orientation. These accumulating pressures of marketisation, globalisation and to some extent, the presence of private and corporate HEIs in South Africa, further gravitate towards public universities to produce graduates that are able to contribute to the labour market. In the past, public universities were accustomed to government financing, which is not adequate anymore in the present economic climate. This has ratcheted up the levels of complexity present within universities to find new sources of funds as public financing continues to wither, giving way to flows from market-related factors such as huge corporations (Mainardes, Raposo \& Alves, 2014). This changing scenario has led researchers to examine how public HEIs can effectively improve their strategic intent to remain competitive, find innovative ways to withstand the economic vulnerability and at the same time serve their constituencies (Bowen \& Fincher, 1996). These pressures have catapulted HEIs efforts in developing better and more efficient strategies in order to be recognised regionally, nationally and internationally as a university of choice (SARUA, 2012). Further, like comprehensive and traditional universities in South Africa, 
UoTs are called upon also to generate relevant and applicable knowledge and transfer high-level skills for the labour market (RSA, 2013:27).

Since 1994, numerous changes have taken place in the university landscape. Via a series of mergers and incorporations, South Africa now has 23 public universities. These comprise 11 traditional universities, six universities of technology (previously known as technikons) and six comprehensive universities (those that combine the functions of traditional universities and universities of technology). In 2014, two HEIs were introduced in the Northern Cape and Mpumalanga provinces, which were eventually transformed into universities, namely Sol Plaatje University and University of Mpumalanga (RSA, 2013: 27). However, with the advent of UoTs within the new government dispensation in 2004, stand-alone UoTs seem to be lonesome, while comprehensive and traditional universities trail blazer and some incorporating the best of both worlds in terms of infrastructure, facilities and staffing (Du Pre, 2009). In congruency with the White Paper for PostSchool Education and Training and the Department of Education and Training's (DHET) primary focus is on promoting the improvement of quality and building appropriate diversity as well as to improve articulation between higher education institutions and between universities and other post-school institutions (RSA, 2013:130). Market orientation (MO) is seen as one of the ways to steer UOTs towards a more sustainable learning environment to become socially relevant. A source of inspiration often begins with a UoT marketing its services, courses, academics, infrastructure and resources to give credence to its vision and mission (Penceliah, 2004).

Although marketing literature is replete with definitions, the commonly cited are those of Narver and Slater (1990), and Kohli and Jaworski (1990). Narver and Slater (1990:21) define MO as "an organisational culture that effectively creates the behaviours necessary for the creation of superior value for buyers and superior performance for the business". On the other hand, Kohli and Jaworski (1990:6) define MO as an organisationwide generation of marketing intelligence relating to current and future customer needs, dissemination of the intelligence across departments, and organisation-wide responsiveness to it". MO is also seen to have affected in many areas of HEIs such as having well-known curriculum with state-of-art technology to drive learning and learning environments. However, these imperatives come with costs associated with infrastructure, appropriate staff and top management with a management and marketing philosophy to succeed. Against this background of increasing competition, UoTs need to market themselves more explicitly (Hemsley-Brown \& Oplatka, 2010).

As in other countries, HEIs in South Africa are faced with a dilemma where a significantly enormous sector is characterised by fierce competition for market share. HEIs were previously understood as experiences of a few but in the last two decades they have now become a normal part of the experiences of a larger and more diverse student population (Mitra, 2009). As a result, HEIs were compelled to find innovative ways to increase their competitive advantage as the sector went through an essential transformation. It has been argued that new HEI environments in South Africa replicate that which has driven business organisations to embrace marketing as a key strategic option due to radical transformation in South Africa. These transformations were promoted voluntarily by HEIs due to the pressures that exist today as a response to the demands of the market and orientation of university curricula. HEIs transformation management involved numerous aspects that had to be considered in addition to making educational, pedagogical and didactical decisions. These include, inter alia, social, cultural, ethical, environmental, technological, management and organisational considerations (Badat, 2007). Maringe and Foskett (2002:47) concluded that the universities of the region are at different stages of marketisation and their levels of marketing sophistication and understanding, which closely resemble those in the business sector, vary from institution to institution.

Whilst the concept of MO has emerged from conventional marketing (Mercer, 1998:2), it has evolved over time, with the most enduring theme being the centrality and sovereignty of stakeholders (Naude \& Ivy, 1999:12). Kotler (2003:13) affirms that the key to achieving the organisational goals depends on determining the needs and wants of target markets and by delivering the desired customer satisfaction more effectively and efficiently than competitors deliver. A further stance cited within the definition necessitates institutions being socially responsible, embracing the notion of conducting business with the long-term interests of the consumers in an unambiguous manner (Batty, 2000:23). Essentially, the societal concept appeals to HEIs to be ethical and to embrace a social responsibility consciousness that rejects the idea of driving products and 
services at any cost. MO strategy thus relates to the development of an institution's appropriate marketing mix (Mazzarol \& Souter, 1999:291). UoTs are the focus of the study as they also experienced radical transformation over the past decades. Being a new HE institution, UoTs provide a good pedestal for this study as is they are major role-players in the knowledge and information technology environment. The present study is an attempt to fill part of the gap and open a window for research to understand the processes and factors involved in MO among UoTs. The primary objective of this study is to establish the factors that contribute to MO among UoTs in South Africa.

\section{Market orientation}

Despite the rapidly growing literature on MO, very few organisations actually implement the concept. One of the main problems contributing to this is that there is not a single unified concept of what is meant by MO. Hence, these diverse interpretations and definitions led to difficulties in the adoption and implementation of the concept. In the 1980s, efforts were undertaken to define or operationalise a MO focused on customers with very little on companies or the organisations (Venkatesan, 2000:1314). It is also interesting to note that there has been some differentiation in the literature on the use of terms market orientation and marketing orientation. The term market orientation, however, is preferred over marketing orientation as it emphasises an organisation-wide application of marketing (Kohli \& Jaworski, 1990:6; Narver \& Slater, 1990:21). Although the marketing literature is replete with definitions, the commonly cited are those of Narver and Slater (1990) and Kohli and Jaworski (1990). Narver and Slater (1990:21) define MO as "an organisational culture that effectively creates the behaviours necessary for the creation of superior value for buyers and superior performance for the business". On the other hand, Kohli and Jaworski (1990:6) posit, "market orientation is the organisation-wide generation of marketing intelligence pertaining to current and future customer needs, dissemination of the intelligence across departments, and organisation-wide responsiveness to it".

Hence, a proliferation of two overlapping streams of MO research was witnessed in the development and growing acceptance of the MO construct in the 1990s. The behavioural stream conceptualised by Kohli and Jaworski (1990:6) relates to specific actions or behaviours necessary to accomplish a market-orientated philosophy, while the cultural and organisational attitude stream conceptualised by Narver and Slater (1990:21) is reflective of the underlying characteristics of the organisations (Crittenden, Crittenden, Ferrell, Ferrell \& Pinney, 2011:73). According to the former, MO is seen as a set of behaviours representing the implementation of the marketing concept and comprises market intelligence generation, market intelligence dissemination and responsiveness. The latter view MO as an organisational culture consisting of three components, namely customer orientation, competitor orientation and inter-functional co-ordination. Alhakimi and Baharun (2009:48) integrated these components of MO.

The complementary nature of these two perspectives emerges from the appreciation that unless an institution has developed a certain attitude, the strategies intended to maximise its adaptation to the market cannot be designed. Moreover, strategies designed to increase the degree of the institution's adaptation to the market cannot be executed unless the preoccupation to do so is acknowledged and appreciated (Avlontis \& Grounaris, 1999). Therefore, the MO of HEIs is presented as a convergence of marketing and strategic management thinking (Binsardi, 2003). While there is no general agreement in the literature on the definition of MO (Rivera-Camino \& Molero Ayala, 2010; Ross, Grace \& Shao, 2012), the converged approach to MO, incorporating the MKTOR scale of Narver and Slater (1990) and the MARKOR scale of Kohli and Jaworski (1990), is used in this study to capture a comprehensive view of MO. This view is based on the components of MO identified by the authors among UoTs. In this context, MO components are regarded as means that enable managers to focus on activities, which ultimately influence the direction of an organisation and performance improvement (Tomaskova, 2008:14). These components are briefly discussed.

Intelligence generation: Intelligence generation entails the collection of information through formal and informal means about students, competitors and their actions, industry and business needs and preferences (Hemsley-Brown \& Oplatka, 2010:209). It also includes information on the latest government regulations and technological changes taking place in the environment (Kaynak and Kara, 2002). HEIs in South Africa are obliged to submit annual reports on their performance while meeting the expectations of a range of stakeholders. 
Intelligence dissemination: Intelligence dissemination refers to the process and extent of market information exchange within a given organisation (Kohli, Jaworski \& Kumar, 1993). Part of the organisations ability to adapt to market needs is how effectively it communicates and disseminates market intelligence among the functional areas (Lafferty \& Hult, 2001:97). Unless market intelligence is communicated throughout the organisation, it is of little use in decision-making (Kohli \& Jaworski, 1990). Effective dissemination of market intelligence, therefore, provides a shared basis for concerted actions by different departments (O'Connel, 2001:5).

Responsiveness to intelligence information: Responsiveness relates to the action taken in response to intelligence information that has been generated and disseminated. This requires a certain level of guidance from top management in the application of marketing tools to elicit favourable market responses. According to Kohli and Jaworski (1990), this can include, among others, selecting target markets, designing and offering products/services that cater for current and anticipated needs in a way that elicits favourable end customer response. In addition, employees need to be taught to recognise and respond to the significance of market intelligence. Unless an organisation responds to the information obtained, nothing is accomplished.

Customer orientation: Customer orientation represents superior skills in understanding and satisfying students and involves developing an understanding of the needs of current and future students (Day \& Nedungadi, 1994). Institutions must have sufficient understanding of their target market and be able to create superior value for them continuously during the entire value chain (Day \& Wensley, 1988). Through this approach, it would be possible to be more innovative and implement improvement for future students based on their anticipated needs (Hemsley-Brown \& Oplatka, 2010).

Competitor orientation: For HEIs to be competitor-oriented, they must recognise both customers and competitors, since both appear in the marketplace (Hunt \& Morgan, 1995). Narver and Slater (1990) argue that market-oriented organisations focus on not only customers, but also on competitors and this involves tracking competitor's actions ((Gray, Osborne \& Mathear, 2000). The analysis of competitors' long-term capabilities, strengths and weaknesses is a key factor in determining MO and culture (Harrison \& Shaw, 2004). HEIs must gather intelligence on the short- and long-term strengths, weaknesses, capabilities and strategies of both the key current and the key potential competitors (Day \& Wensley, 1988).

Inter-functional coordination: The integration and coordination of all functions within a university is of paramount importance for the implementation of MO. This also applies to the integration and coordination of all the university's resources in creating superior value for target customers (Narver \& Slater, 1990). In this regard, the cooperation of the different units of the university is required (Rivera-Camino \& Ayola, 2010). For example, it is not only the sole responsibility of the recruitment department of the university to attract students, but it is the responsibility of every staff member in the university community. In doing so, faculties should also have full access to information about competition, the market environment and the community so that they too can play a role in attracting students.

\section{Methodology}

Data for the study were collected from academics in five of the six UoTs in South Africa using a quantitative research approach through a structured questionnaire.

Sample: The sample comprised full-time academics from the participating UoTs, employed for more than three years, who were also au fait with the functioning of their institutions. Academics were chosen, as it appeared that they were a desirable segment for determining the underlying dimensions of MO in their respective units and institutions. A non-probability convenient sampling technique using a cross-sectional survey was used in line with similar previous studies (Ivy, 2001; Rindfleish, 2003; Maringe, 2005; Zebal \& Goodwin, 2012).

Measuring instrument: A structured questionnaire was chosen as a measuring instrument as it is simple to administer and reduces the variability in the results that may be caused by differences in other types of interviews (Malhotra, 2010). An instrument developed by Zebal (2003) and further modified for university 
context by Ma and Todorovic (2011) was used as a basis of the study. These items embraced variables contained from the scales developed by Narver and Slater (1990), and Kohli and Jaworski (1990). Minor changes in wording, where applicable, were affected in order to fit the current research content and purpose. The items on the components of MO were based on a five-point Likert scale with one denoting strongly disagree to five denoting strongly agree. In addition, the demographic profiles of respondents were collected.

Data collection and procedure: A self-reported questionnaire was distributed to a convenient sample. An enclosed letter, clearly outlining the purpose of the study, was attached to the questionnaire. Of the 1250 questionnaires that were distributed, 518 questionnaires were returned of which 11 were incomplete and discarded. A total of 507 questionnaires were used for data analysis finally. Various ethical considerations were adhered to in administering the questionnaire. The participants' rights to anonymity, confidentiality, privacy or non-participation, protection from harm and victimisation were respected.

Reliability, validity and accuracy analysis: For the purpose of determining the reliability of this study, Cronbach alpha coefficients and composite reliability (CR) values were computed for the measurement scale (Table 1). Both reliability measures were used with a threshold value of 0.7 (Malhotra, 2010). Furthermore, a cut-off point of 0.50 on the item-to-total correlations was maintained. The Cronbach alpha values ranged from 0.817 to 0.926 , which indicates a high level of reliability (Nunnally, 1978). Convergent validity of the measures was then assessed by calculating the factor loadings, using exploratory factor analysis. Table 2 shows that the standardised loadings ranged from 0.513 to 0.826 , which were above the commonly accepted minimum value of 0.50 (Teo \& King, 1996). Discriminant validity of the measures was assessed consistent with Jayanti and Burns (1998). This analysis technique involves correlating all the measures used as well as measuring the coefficient correlations against the alpha coefficients of the scales. As seen in Table 1, no correlation coefficient was higher than the alpha coefficient of the scales. These outcomes confirm the discriminant validity of the scales used. Discriminant validity was also assessed by checking if the AVE value was greater than the highest shared variance (SV) (Fornell \& Larcker, 1981). In Table 1, all AVE values were higher than the SV, further affirming discriminant validity.

Table 1: Reliability, validity and accuracy analysis statistics

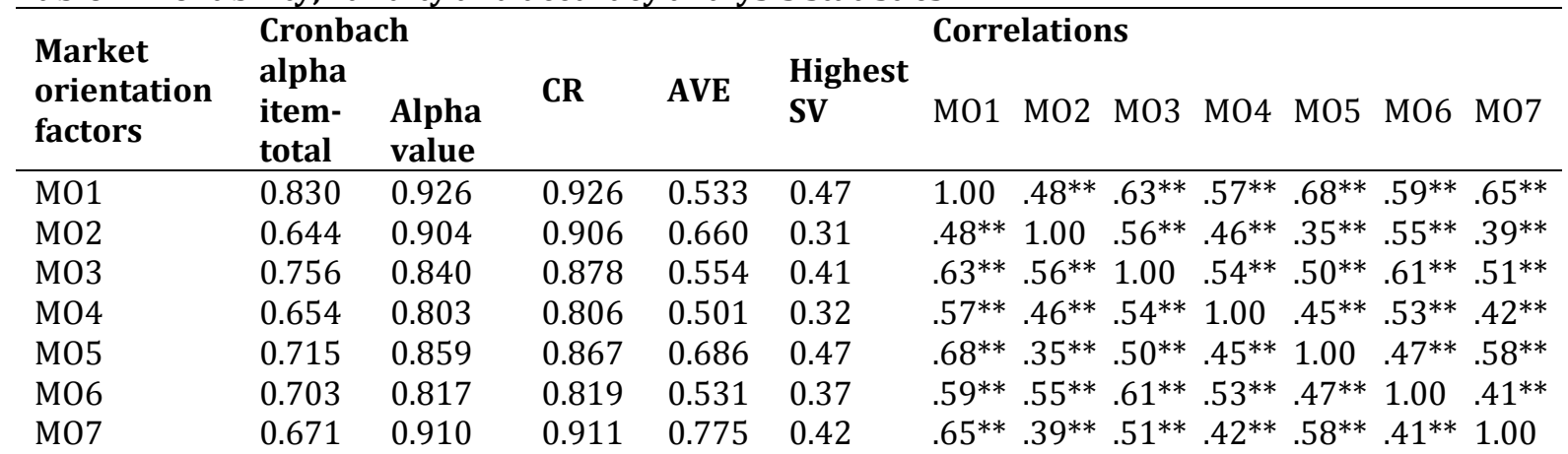

$\mathrm{CR}=$ composite reliability; $\mathrm{AVE}=$ average variance extracted; $\mathrm{SV}=$ shared variance.

** Correlation is highly significant at the 0.01 level ( 2 tailed).

$\mathrm{MO}=$ market orientation. Item total = Item total correlations

\section{Results}

Sample profile: There were more male academics $(n=220 ; 43 \%)$ compared to female academics $(n=287$; $57 \%)$ in the sample. The majority of the respondents were between 30 to 39 years $(n=172 ; 34 \%)$, followed by the age group between 40 and 49 years $(n=160 ; 32 \%)$, the age group between 30 to 39 years, $(n=81 ; 16 \%)$, the age group between $50-59$ years, $(n=66 ; 13 \%)$ and the age group of over 60 years, $(n=28 ; 5 \%)$. Junior lecturers comprised majority of the sample ( $\mathrm{n}=246 ; 49 \%)$, followed by those academics who were senior lecturers/associate professors ( $\mathrm{n}=209 ; 41 \%)$. Heads of departments (HODs), deans/professors comprised the remainder of the sample $(n=52 ; 10 \%)$. 
Exploratory factor analysis (EFA): EFA was conducted on the data set to identify the different factors that contribute to market orientation practices and usage within UoTs. The appropriateness of factorability on the data set was first established. This was accomplished through the Kaiser-Meyer Olkin (KMO) and the Bartlett's test of sphericity measures of sampling adequacy. The KMO test yielded sampling adequacy of 0.955 , which is within the acceptable range of between 0.5 and 1.00 (Malhotra 2010) and the Bartlett's test of sphericity results revealed significant chi-squares of 12537.054 ( $\mathrm{df}=630 ; \mathrm{p}=0.000<0.05$ ). The two tests affirmed that patterns of correlation are compact and that factor analysis is appropriate for use on the data set (Kaiser, 1974:35). The percentage of variance explained (>50\%) and an eigen value (equal to or greater than 1) criterion guided the extraction of factors (Bradley, 2010; Huck, 2012). The procedure resulted in seven extracted factors, which are reported in Table 2.

Table 2: Factor loading matrix

\begin{tabular}{|c|c|c|c|c|c|c|c|}
\hline Description & $\begin{array}{l}\text { Factors } \\
\text { MO } 1\end{array}$ & MO 2 & M0 3 & MO 4 & MO 5 & MO 6 & MO 7 \\
\hline $\begin{array}{l}\text { Collection of information about the social } \\
\text { and economic situation }\end{array}$ & .615 & .140 & .231 & .335 & .299 & -.055 & .024 \\
\hline $\begin{array}{l}\text { Collection information about other } \\
\text { disciplines and departments }\end{array}$ & .630 & .153 & .229 & .390 & .231 & .006 & -.040 \\
\hline $\begin{array}{l}\text { Profile changes demanded by the labour } \\
\text { market }\end{array}$ & .577 & .137 & .155 & .394 & .225 & .123 & .092 \\
\hline $\begin{array}{l}\text { Review course development efforts in } \\
\text { line with industry }\end{array}$ & .627 & .139 & .152 & .233 & .126 & .217 & .269 \\
\hline $\begin{array}{l}\text { Student satisfaction disseminated at all } \\
\text { levels }\end{array}$ & .611 & .175 & .175 & .209 & .002 & .227 & .246 \\
\hline Coordination of academics activities & .693 & .163 & .212 & .031 & .033 & .278 & .197 \\
\hline $\begin{array}{l}\text { Dissemination of industry satisfaction } \\
\text { with our graduates at all levels }\end{array}$ & .680 & .096 & .107 & .038 & .155 & .200 & .253 \\
\hline Survey of our industry & .673 & .081 & .166 & .116 & .209 & .193 & .248 \\
\hline $\begin{array}{l}\text { Inter-functional meetings to analyse } \\
\text { important market information }\end{array}$ & .570 & .218 & .135 & .150 & .336 & .154 & .246 \\
\hline $\begin{array}{l}\text { Integration of business processes and } \\
\text { departments }\end{array}$ & .529 & .321 & .197 & .112 & .362 & .174 & .108 \\
\hline $\begin{array}{l}\text { The various departments informed about } \\
\text { peer departments of other universities }\end{array}$ & .570 & .232 & .198 & .103 & .361 & .154 & .212 \\
\hline Prioritising meeting with students & .135 & 609 & .308 & .076 & .216 & .153 & .081 \\
\hline $\begin{array}{l}\text { Dedication of departments in serving the } \\
\text { needs of students }\end{array}$ & .140 & .765 & .215 & .109 & .158 & .142 & .055 \\
\hline Student learning experience contribution & .175 & .819 & .195 & .173 & .088 & .164 & .110 \\
\hline Sharing of resources by departments & .185 & .826 & .112 & .158 & .061 & .164 & .108 \\
\hline Talking to other department members & .176 & .791 & .123 & .209 & .061 & .164 & .166 \\
\hline $\begin{array}{l}\text { Programmes response to existing } \\
\text { demands }\end{array}$ & .256 & .272 & .599 & .142 & .289 & .275 & .169 \\
\hline $\begin{array}{l}\text { Research helps to solve problems in } \\
\text { society }\end{array}$ & .267 & .206 & .639 & .223 & .298 & .217 & .142 \\
\hline $\begin{array}{l}\text { Research covers societal and business } \\
\text { demand }\end{array}$ & .329 & .147 & .638 & .212 & .307 & .162 & .179 \\
\hline $\begin{array}{l}\text { Monitoring and assessing commitment to } \\
\text { serving students' needs }\end{array}$ & .230 & .168 & .656 & .264 & .198 & .236 & .171 \\
\hline $\begin{array}{l}\text { Strategies driven by the goal of enhancing } \\
\text { students learning experience }\end{array}$ & .166 & .195 & .653 & .033 & -.012 & .025 & .034 \\
\hline $\begin{array}{l}\text { Competitive advantages based on } \\
\text { understanding of students needs }\end{array}$ & .100 & .306 & .513 & .199 & -.044 & .256 & .264 \\
\hline $\begin{array}{l}\text { Collection of information about other } \\
\text { disciplines and departments off }\end{array}$ & .270 & .239 & .182 & .675 & .075 & .151 & .079 \\
\hline We collect information about training and & .158 & .237 & .134 & .662 & -.050 & .207 & .124 \\
\hline
\end{tabular}


research carried out in private

universities

\begin{tabular}{|c|c|c|c|c|c|c|c|}
\hline $\begin{array}{l}\text { Academics spends time discussing } \\
\text { students' future needs }\end{array}$ & .148 & .158 & .096 & .737 & .193 & .140 & .190 \\
\hline $\begin{array}{l}\text { Held meetings with those who hire our } \\
\text { students }\end{array}$ & .160 & .046 & .152 & .677 & .276 & .128 & .052 \\
\hline $\begin{array}{l}\text { Flexibility in adapting or changing course } \\
\text { material }\end{array}$ & .291 & .188 & .057 & .248 & .632 & .261 & .144 \\
\hline $\begin{array}{l}\text { Held meetings to discuss the most } \\
\text { relevant research issues }\end{array}$ & .349 & .122 & .220 & .136 & .708 & .108 & .247 \\
\hline $\begin{array}{l}\text { Adapting teaching and research work to } \\
\text { the needs of business and industry }\end{array}$ & .312 & .129 & .215 & .163 & .711 & .070 & .252 \\
\hline Rapid distribution of information & .223 & .223 & .305 & .135 & .042 & 658 & -.024 \\
\hline $\begin{array}{l}\text { Relevant marketing information } \\
\text { distribution to all }\end{array}$ & .207 & .173 & .234 & .190 & .106 & .720 & .090 \\
\hline $\begin{array}{l}\text { Review of the changes in the higher } \\
\text { education }\end{array}$ & .246 & .278 & .101 & .200 & .138 & .660 & .141 \\
\hline Students complaints are addressed & .246 & .210 & .067 & .212 & .392 & .561 & .104 \\
\hline Prevailing atmosphere & .337 & .183 & .217 & 159 & .200 & .098 & .731 \\
\hline $\begin{array}{l}\text { Working relationship in various } \\
\text { departments }\end{array}$ & .349 & .146 & .126 & .181 & .219 & .069 & .788 \\
\hline Major market information spreading & .359 & .169 & .204 & .112 & .226 & .086 & .731 \\
\hline Eigen value & 15.829 & 2.406 & 1.525 & 1.312 & 1.195 & 1.074 & 1.012 \\
\hline Total variance explained & 44.053 & 6.683 & 4.235 & 3.645 & 3.319 & 2.985 & 2.811 \\
\hline Cumulative variance explained & 44.053 & 50.735 & 54.971 & 58.615 & 61.935 & 64.919 & 67.731 \\
\hline $\begin{array}{l}\text { MO 1=Market intelligence generation; MO } \\
\text { M04=Market intelligence dissemination; } \\
\text { implementation; MO7=Inter-departmenta }\end{array}$ & $\begin{array}{l}\text { =Inter-fu } \\
\text { O5=Intell } \\
\text { dynamics }\end{array}$ & $\begin{array}{l}\text { ctional c } \\
\text { gence re }\end{array}$ & $\begin{array}{l}\text { ordinati } \\
\text { ponse de }\end{array}$ & ign; $N$ & $\begin{array}{l}\text { tudent } 0 \\
\text { =Intellig }\end{array}$ & ientatior & se \\
\hline
\end{tabular}

Measurement model assessment through confirmatory factor analysis (CFA): After the extraction of factors through an exploratory factor analysis procedure, confirmatory factor analysis (CFA) using AMOS 21.0 was performed to assess the usefulness of the factors and validate the measurement model. Model fit (misfit) is assessed using indices suggested by Bagozzi and Yi (2012) as follows: chi-square $\chi^{2} / \mathrm{df}(<0.3), \mathrm{cmin} / \mathrm{df}$ $(<0.3)$, increment fit index (IFI>0.90), comparative fit index (CFI>0.90) and the root mean square error of approximation (RMSEA<0.08).

Discussion: Table 2 displays the items comprising the MO measure for UoT settings. The factor structure shows seven elements of MO. These seven components were labelled market intelligence generation, interfunctional coordination, student orientation, market intelligence dissemination, intelligence response design, intelligence response implementation and inter-departmental dynamics.

Factor 1, Market intelligence generation, (eigenvalue=15.829), accounts for approximately 44 percent of the total explained variance and consisted of 11 items with factor loadings ranging from 0.529 to 0.693 . The factor relates to organisational activities that accompany the generation of market information as a source of ideas in implementation of the marketing concept across departments and individuals within the universities. The starting point of a market-oriented university is market intelligence philosophy that encompasses all the informal as well as formal means of generating market intelligence about students, competitors, industry and business needs and preferences (Penceliah, 2004:186; Hemsley-Brown \& Oplatka, 2010:209). This includes monitoring current and prospective students, marketing activities implemented by other institutions, employing organisations and detecting fundamental shifts in higher education environments (Asaad, Cohen \& Melewar, 2008:4). The generation of market information can be fostered through competitor orientation and customer orientation (Carr \& Lopez, 2007:13). Market intelligence includes, amongst others, systematic methods of organising and retrieving current market information, intelligence network to collect and share information with everyone within the institution, systematic research approach to gather new market information, and process of analysing information for decision-making purposes (Drysdale, 1999:28-29). 
However, it is important to note that intelligence generation is not the exclusive responsibility of a marketing department only and unless market intelligence is communicated throughout the organisation, it becomes of little use in decision-making. This calls for UoTs to adapt to market needs through communicating and dissemination of market intelligence amongst functional areas within the university (Gray, Osborne \& Mathear, 2000:432).

Factor 2, Inter-functional coordination, (eigenvalue=2.406), accounts for approximately 7 percent of the total explained variance and consisted of five items with factor loadings ranging from 0.609 to 0.826 . Interfunctional coordination relates to the capability of a university to achieve the cooperation of the different units in market intelligence generation (Rivera-Camino \& Ayola, 2010:5). This can be achieved through integration and coordination of the UoTs resources (Hemsley-Brown \& Oplatka, 2010:211). MO stresses inter-functional coordination because coordination and teamwork among different functional units and employees is necessary for efficient and effective business administration in UoTs (Voon, 2008:220). Through this approach, it would then be possible to be more innovative and implement improvement plans for future students based on anticipated needs. The key indicator of this characteristic is the total commitment of all members to a marketing philosophy (Drysdale, 1999:28). In developing effective inter-functional coordination, the marketing unit or any other advocate department must be extremely sensitive and responsive to the perceptions and needs of all other departments in business. Typical behaviour includes all departments and teams sharing market information, integrating strategies and willing to share resources in order to offer superior value to students and other stakeholders. Hence, the mechanism enables the necessary strategic orientation to work jointly.

Factor 3. Student orientation, (eigenvalue=1.525), accounts for approximately 4 percent of the total explained variance and consisted of six items with factor loadings ranging from 0.513 to 0.656 . At the simplest level, universities can regard students as their primary focus as they are the ones who enter into relationships with HEIs (Naude \& Ivy, 1999:127). Lindsay and Rodgers (1998:167) affirm that students are the ones who receive the benefit of the product or service and they are the ones who put their hands in their pockets to pay for it. Both of these conditions can apply to the student as well as the employing organisation. Therefore, the employing organisation can also be perceived as the university's customer. Consequently, both the student and the employing organisations are the principal customers of HEIs (Asaad et al., 2008:3). However, in this regard the role of other stakeholders like society and government should not be disregarded due to the influential role they play towards student's wants and preferences. Despite the unresolved debate whether or not students should be considered as customers, Rivera-Camino and Ayala (2010:4) maintain that customer orientation should be considered as an important component of market orientation.

Factor 4. Market intelligence dissemination, (eigenvalue=1.312), accounts for approximately 4 percent of the total explained variance and consisted of four items with factor loadings ranging from 0.662 to 0.737 . The intelligence generated through market intelligence generation, needs to be disseminated throughout the university both hierarchically and horizontally. While information is readily available, most HEIs find it difficult to disseminate market intelligence that will assist them to develop a quality image, which is a prerequisite to achieve sustainable competitive advantage and a university of choice (Caruana, Ramaseshan \& Ewing, 1988:5). HEIs must then adapt to market needs through communicating and dissemination of market intelligence amongst functional areas (Gray et al., 2000). A flexible structure in an organisation could increase the flow of the information and push the decision-making to places where changes are made (Alhakimi \& Bahuran, 2009:45) via cross-functional teamwork, flatter hierarchies and employee empowerment $\left(\mathrm{O}^{\prime}\right.$ Connel, 2001:5).

Factor 5. Intelligence response design, (eigenvalue=1.195) accounts for approximately 3 percent of the total explained variance and consisted of three items with factor loadings ranging from 0.632 to 0.711 . Response design takes the form of selecting target markets, designing services that cater to current and anticipated needs and promoting the services in a way that elicits favourable customer response (Zebal \& Goodwin, 2012:345). Response design is one of the aspects relating to a successful response to the information generated about the market (Lings \& Greenly, 2005:299) and involves the planning of programmes based on the needs of students, community, business and industry as a result of generated and disseminated market intelligence (Penceliah, 2004:200). An organisation can generate intelligence and 
disseminate it internally, but unless it responds to market needs, very little is accomplished (Kohli \& Jaworski, 1990:6). Responsiveness is another behavioural element of MO, which refers to the action taken in response to intelligence that is generated and disseminated such as taking action based on the intelligence (Zebal, 2003:53).

Factor 6. Intelligence response implementation, (eigenvalue=1.074), accounts for approximately 3 percent of the total explained variance and consisted of four items with factor loadings ranging from 0.661 to 0.720 . Response implementation involves the application of programmes geared towards the student or industry as a result of response design (Penceliah, 2004:223). Responding to changes taking place in higher education will in turn have an effect on generating further information. The core business of any HEI is its development of the curricula as a response to market intelligence generated and disseminated for the universities. Universities, therefore, need to design and align their marketing to reflect their core purpose in developing curriculum (Maringe, 2005:572). Finally, responsiveness addresses the execution of a plan of action or market-focused strategy (Zebal \& Goodwin, 2012:345) and means implementing and altering products and services in response to customers current and future needs (Zebal, 2003:57).

Factor 7. Inter-departmental dynamics (eigenvalue=1.012), accounts for approximately 3 percent of the total explained variance and consisted of three items with factor loadings ranging from 0.731 to 0.788 . This factor relates to manifestations of cohesion between staff members, which subsequently influences MO behaviours (Caruana et al., 1988:57). Interdepartmental dynamics is linked closely to the intensity of MO within an institution, which is understood to entail the existence of affinity and understanding among departmental members (Flavian \& Lozano, 2006:456). Trueman (2004:8) argues that the existence of cohesion facilitates the generation of market information, its dissemination within the organisation and enables the development of a rapid response to information.

Acceptable model fit was confirmed by the chi-square $\left(\chi^{2}\right)$ value of 1698.853 with 573 degrees of freedom at a p value $=0.000<0.05 ; \mathrm{CMIN} / \mathrm{DF}=2.965 ; \mathrm{IFI}=0.908 ; \mathrm{CFI}=0.908$ and $\mathrm{RMSEA}=0.062$. The CFA results provided revealed that the overall fit of the measurement model was satisfactory (Fornell \& Larcker, 1981; Browne \& Cudeck, 1993) as it achieved the suggested thresholds, suggesting that the model converged well and could be a plausible representation of the empirical data structures collected among UoTs in South Africa.

Research contributions and implications for practioners: The study contributes a new direction in the research on MO by opening up a debate on the importance of MO practices in UoTs and identifying the components of MO that can be operationalised among UoTs in South Africa. For practitioners and academics, the study presents a list of factors that they may wish to consider in attempting to generate a greater degree of MO among UoTs. It is also interesting to note that the measures/scales applied fit very well to the UoTs context assessed by the statistical measures of accuracy tests identified in the study, which should provide avenues for researchers to explore components of MO within the HE landscape further. The support of those making strategic decisions is needed to garner the necessary support to other employees in UoTs, especially top and senior management's buy-in and support. To this end, managers and marketers are encouraged to acquire skills, knowledge, experience and other capabilities continuously, which will enable them to build up and attain higher levels of MO. Top management as well as academics need to optimise the effectiveness of their MO strategies. An iterative feedback mechanism needs to be designed in order to evaluate the success of the strategy. All this could be achieved by deliberate articulation of organisational commitment to the principles of MO.

Limitations and future research opportunities: The use of academics only as respondents makes it difficult to generalise the findings of the study to other university categories or environments such as traditional or comprehensive universities in South Africa. As a result, the respondents used in the study are not representative of the broader South African HEIs academic population. The adoption of a non-probability convenience sampling technique in selecting the sample increased the study's susceptibility to sampling bias. To enhance external validity, future research is warranted to obtain a representative sample from various respondents including non-academics. A single cross-sectional research design used in the study lacked the depth of a longitudinal study. South African HEIs should engage in longitudinal studies to establish the causal relationships among the variables and improve their understanding of their institutions' customers, 
stakeholders and competitors needs in order to implement MO. Furthermore, instead of adopting a purely quantitative design, a mixed method could be considered to refine the results of future studies on this topic. A qualitative design may be helpful in making follow-ups to the responses provided in the quantitative design and it will be worthwhile to utilise both qualitative and quantitative paradigms to supplement each other.

\section{Conclusion}

The purpose of this paper was to identify the MO constructs for UoTs by bringing forward the concept of MO in South Africa, applied through HE. While research on MO applied in HE in SA is still developing, the study provides an opportunity for UoTs to improve the idea of MO by embracing the concept. This academic enquiry explored and highlighted the significance of MO components on HE. The findings of the study indicated that the MO of UOTs in South Africa was fundamentally determined by seven distinct, but interrelated, factors within the institutions, namely market intelligence generation, inter-functional coordination, customer orientation, market intelligence dissemination, intelligence response design, intelligence response implementation and interdepartmental dynamics. Most of these factors delineated in this study, are largely controllable by senior executives and marketing operatives, thereby allowing a purposeful implementation of MO. Future studies could expand the factors that were used in this study to better understand the implementation of MO and the relationship between its components. MO has an important role to play, as it is a boundary-spanning institutional function, through its constant interface with external environments at large and with customers, competitors and channel members in particular.

\section{References}

Alhakimi, W. \& Baharun, R. (2009). An integrative model of market orientation constructs in consumer goods industry: empirical evidence. International Management Review, 6(2), 40-54.

Altbach, P. G. (2010). University ranking season is here. Economic and political weekly (Mumbai, India) (December 4, 2010): 14-17.

Asaad, Y., Cohen, G. \& Melewar, T. C. (2008). Antecedents and consequences of market orientation in universities: literature review and conceptual framework. Conference proceedings, Academy of Marketing Conference, 7-8, 1-11.

Avlontis, G. \& Gounaris, S. (1999). Marketing orientation its determinants: an empirical analysis-increased market oriented activity what the literature suggests. Journal Market Focus Management, 4, 77-92.

Badat, S. (2007). Higher education transformation in South Africa post 1994. Towards critical assessments. Pretoria: CEPD.

Bagozzi, R. P. \& Yi, Y. (2012). Specification, evaluation and interpretation of structural equation models. Journal of the Academy of Marketing Sciences, 40(1), 8-34.

Batty, P. (2000). Scholar attacked for links to junta. Times Higher Education Supplement, 16 March: 23.

Binsardi, F. E. (2003). International marketing of British education: research on the students' perception and the UK market penetration. Marketing Intelligence \& Planning, 21(5), 318 - 327.

Bowen, H. \& Fincher, C. (1996). Investment in learning: The individual and social value of American Higher education (2nd ed.). New Brunswick: Transaction Publishers.

Bradley, N. (2010). Marketing research: tools and techniques. 2nd ed. New York: Oxford University Press.

Browne, M. W. \& Cudeck, R. (1993). Alternative ways of assessing model fit. In K.A. Bollen, \& J.S. Long (Eds.), Testing Structural Equation Models (pp. 136-192). Newbury Park, CA: Sage.

Carr, J. C. \& Lopez, T. B. (2007). Examining market orientation as both culture and conduct: modelling the relationships between market orientation and employees responses. The Journal of Marketing Theory and Practice, 15(2), 113-125.

Caruana, A., Ramaseshan, B. \& Ewing, M. T. (1988). Do universities that are more market oriented perform better? International Journal of Public Sector Management, 11(1), 55-70.

Crittenden, V. L., Crittenden, W. F., Ferrell, L. K., Ferrell, O. C. \& Pinney, C. C. (2011). Market orientation sustainability: a conceptual framework and propositions. Journal of the Academy of Marketing Science, 39, 71-85.

Day, G. S. \& Nedungadi, P. (1994). Managerial representations of competitive advantage. Journal of Marketing, $58,31-44$. 
Day, G. S. \& Wensley, R. (1988). Assessing advantage: a framework for diagnosing competitive superiority. Journal of Marketing, 52, 1-20.

Drysdale, L. (1999). Marketing or market orientation: What is the difference? Journal for Gustation Primary School Teachers, 4, 28-29.

Du Pre, R. H. (2009). The place and role of Universities of Technology in South Africa. Bloemfontein: SATN.

Flavian, C. \& Lozano, J. (2006). Organisational antecedents of market orientation in the public university system. International Journal of Public Sector, 19(5), 447-467.

Fornell, C. \& Lacker, L. (1981). Evaluating structural equation models with unobservable variables and measurement error. Journal of Marketing Research, 19(1), 39-50.

Giroux, H. A. (2003). Public spaces, private lives: democracy beyond 9/11. Lanham, MD: Rowman \& Littlefield Publishers.

Gray, B., Osbrone, P. \& Mathear, S. (2000). Are service firms more market oriented? Visionary Marketing for the $21^{\text {st }}$ Century Facing the Challenge, $432-436$.

Harris, L. C. \& Ogbonna, E. (1999). Developing a market-oriented culture: a critical evaluation. Journal of Management Studies, 36(2), 177-196.

Harrison, P. J. \& Shawn, R. N. (2004). Intra-organisational marketing culture and market orientation: a case study of the implementation of the marketing concept in a public library. Library Management, 25(8/9), 391-398.

Hemsley-Brown, J. \& Oplatka, I. (2010). Market orientation in universities. International Journal of Educational Management, 24(3), 204-220.

Hu, L. \& Bentler, P. M. (1999). Cutoff criteria for fit indexes in covariance structure analysis: conventional criteria versus new alternatives. Structural Equation Modeling: A Multidisciplinary Journal 6(1), 1-55.

Huck, S. W. (2012). Reading statistics and research, $6^{\text {th }}$ edition. Person: Boston.M.A.

Hunt, S. D. \& Morgan, R. M. (1995). The competitive advantage theory of competition. Journal of Marketing, $59(2), 1-15$.

Ivy, J. (2001). Higher education institution image: a correspondence analysis approach. The International Journal of Educational Management, 15(6), 276-282.

Jayanti, R. K. \& Burns, A. C. (1998). The Antecedents of preventive health care behaviour: an empirical study. Journal of the Academy of Marketing Science, 26(1), 6-15.

Kaiser, H. F. (1974). An index of factorial simplicity. Psychometrika, 39, 31-6.

Kaynak, E. \& Kara, A. (2002). Consumer perceptions of foreign products: An analysis of product-country images and ethnocentrism. European Journal of Marketing, 36(7/8), 928 - 949.

Kohli, A. K. \& Jaworski, B. J. (1990). Market orientation: the construct, research propositions, and managerial implications. Journal of Marketing, 54(2), 1-18.

Kohli, A. K., Jaworski, B. J. \& Kumar, A. (1993). Markor: a measure of market orientation. Journal of Market Research, 30(4), 467-477.

Kotler, P. (2003). Marketing management. (International edition 20). 11th Edition. Upper Saddle River, New Jersey: Pearson Education.

Lafferty, B. \& Hult, G. T. M. (2001). A synthesis of contemporary market orientation perspectives. European Journal of Marketing, 35(1/2), 92-109.

Lindsay, G. \& Rodgers, T. (1998). Market orientation in the UK higher education sector: the influence of the education reform process 1979-1993. Quality in Higher Education, 4(2), 159-171.

Lings, I. \& Greenly, G. (2005). Measuring internal market orientation. Journal of Service Research, 7(3), 71-94.

Ma, J. \& Todorovic, Z. (2011). Making university relevant: MO as a dynamic capability within institutions of higher learning. Academy of Marketing Studies Journal, 15(2), 1-15.

Mainardes, E. W., Raposo, M. \& Alves, H. (2014). Universities need a market orientation to attract nontraditional stakeholders as new financing sources. Public Organisation Review, 14, 159-171.

Makadok, R. (2001). Toward a synthesis of the resource-based and dynamic capability views of rent creation. Strategic Management Journal, 22(5), 387-401.

Malhotra, N. K. (2010). Marketing research: an applied orientation. 6th ed. Eaglewood Cliffs: Prentice-Hall.

Manz, C. C. \& Sims, P. S. Jr. (1981). Vicarious learning: the influence of modelling on organizational behaviour. Academy of Management Review, 6(1), 105-113.

Maringe, F. \& Foskett, N. H. (2002). Marketing university education: the South African experience. Higher Education Review, 34(3), 35-51. 
Maringe, F. (2005). Interrogating the crisis in higher education marketing: the CORD model. International Journal of Education Management, 19(7), 564-578.

Mazzarol, T. \& Souter, G. N. (1999). Sustainable competitive advantage for education institutions: a suggested model.

Mercer, D. (1998). Marketing for managers. London: Orion Publishing Group.

Mitra, S. K. (2009). Why universities are adopting market oriented management practices? Asian Social Science, 5(3), 137-142.

Morgan, A. N. \& Vorhies, D. W. \& Mason, C. H. (2009). Marketing orientation, marketing capabilities and firm performance. Strategic Management Journal, 30, 909-920.

Narver, J. \& Slater, S. (1990). The effect of market orientation on business profitability. Journal of Marketing, 54(4), 20-35.

Naude, P. \& Ivy, J. (1999). The marketing strategies of universities in the United Kingdom. The International Journal of Education Management, 13(3), 126-134.

Nunnally, J. C. (1978). Psychometric theory. McGraw-Hill Publishing: New York.

O'Connell, M. (2001). Market orientation: the implementation of the marketing concept. ITB Journal, 3, 4-15.

Pallant, J. (2010). SPSS survival manual: a systematic guide to data analysis using SPSS for Windows third edition. Open University Press: McGraw-Hill.

Penceliah, S. (2004). The applicability of market orientation to selected degree programmes at technikons in KwaZulu-Natal. PhD Thesis. North West University.

RSA. Republic of South Africa. (2013). White paper for Post-School Education and Training: building an expanded, effective and integrated post-school system. Department of Higher Education and Training. (p.130). Pretoria: Government Printers

Rindfleish, J. M. (2003).0 Segment profiling: reducing risk in higher education management. Journal of Higher Education Policy and Management, 25(2), 147-159.

Rivera-Camino, J. \& Ayala, V. M. (2010). Market orientation at universities: construct and exploratory validation. Innovar, 20(36), 1-15

Ross, M., Grace, D. \& Shao, W. (2012). Come on higher education, get on with programme! A study of market orientation in international student recruitment. Educational Review, 1, 1-22.

Sarua. (2012). Higher education profiling in the SADC region. Higher Education Institution. Pretoria.

Slater, S. F. \& Narver, J. C. (1995). Market orientation and learning organization. Journal of Marketing, 59, 6374.

Teo, T. S. H. \& King, W. R. (1996). Assessing the impact of integrating business planning and IS planning. Information \& Management, 30(6), 309-321.

Tomaskova, E. (2008). Internal barriers of market orientation application. Economics and Management, 14, 16

Trueman, K. (2004). Market-orientation and local government. barriers and constraints. Political Studies Association, (1), 1-12.

Venkatesan, V. S. (2000). The applicability of some market orientation models to Australians SMEs: an empirical study ANZMAC 2000:1314-1318

Voon, B. H. (2008). SERVMO: a measure for service-driven market orientation in higher education. Journal of Marketing for Higher Education, 17(2), 216-237.

Zebal, M. A. \& Goodwin, D. R. (2012). Market orientation and performance in private universities. Marketing Intelligence and Planning, 30(3), 339-357.

Zebal, M. A. (2003). Market orientation synthesis model for a developing country: the case of Bangladesh, $\mathrm{PhD}$ Thesis Victoria University of Technology: Melbourne Australia. 